\title{
160. On the Postseismic Block Movements in the Tango Earthquake District."
}

\author{
By Chuji TsuBor. \\ Earthquake Research Institute, Tokyo Imperial University. \\ (Rec. Oct. 15, 1928. Comm. by T. TeradA, M.I.A., Nov. 2, 1928.)
}

Immediately after the great earthquake which devastated the district of Tango on March 7th, 1927, the Military Land Survey Department undertook the revision of triangulations and precise levellings over the disturbed area. The postseismic precise levellings have been repeated three times in view of getting information concerning the mode in which the ground in this district settles down after being greatly disturbed by the catastrophe. The writer has recently made an examination upon the results ${ }^{2}$ of these surveys in some detail and found a very remarkable feature in the postseismic minor crustal movements in this district. The object of the present paper is to give a brief summary of these studies together with a probable interpretation of the said feature from the geological point of view.

The dotted lines in Fig. 1 show the levelling routes in the district, all but one of which were newly set up immediately after the earthquake with the above mentioned special purpose. The first of the three surveys was carried out from April 12 to June 16, 1927; the second from June 1 to July 31, 1927; and the third from March 3 to April 20, 1928.

The results of these surveys were subjected to an examination in the following manner. Every turning point with a sharp bend of the levelling route was marked by A, B, C, etc., and every adjacent two of them were connected by a straight line on which the positions of all the bench marks between those points were projected. The amount of the vertical displacement $\Delta h$ of each of these bench marks produced in the interval between two surveys is plotted against its projected position in a rectangular co-ordinate. A few examples of the results are shown in Fig. 2. In representing the movement of the ground, the Kutiôno bench mark was taken as fixed in height throughout these surveys, to which the displacement of all the others was referred. No loss in generality is, of course, introduced by this assumption.

1) The full paper will appear in Bull. Earthq. Res, Inst., 6.

2) The Land Survey Department, Bull. Earthq. Res. Inst., 3 (1927), 4 (1928), 5 (1928). The results have already been discussed by T. Terada and N. Miyabe from the isostatic point of view. these Proc., 4 (1928) 211. 

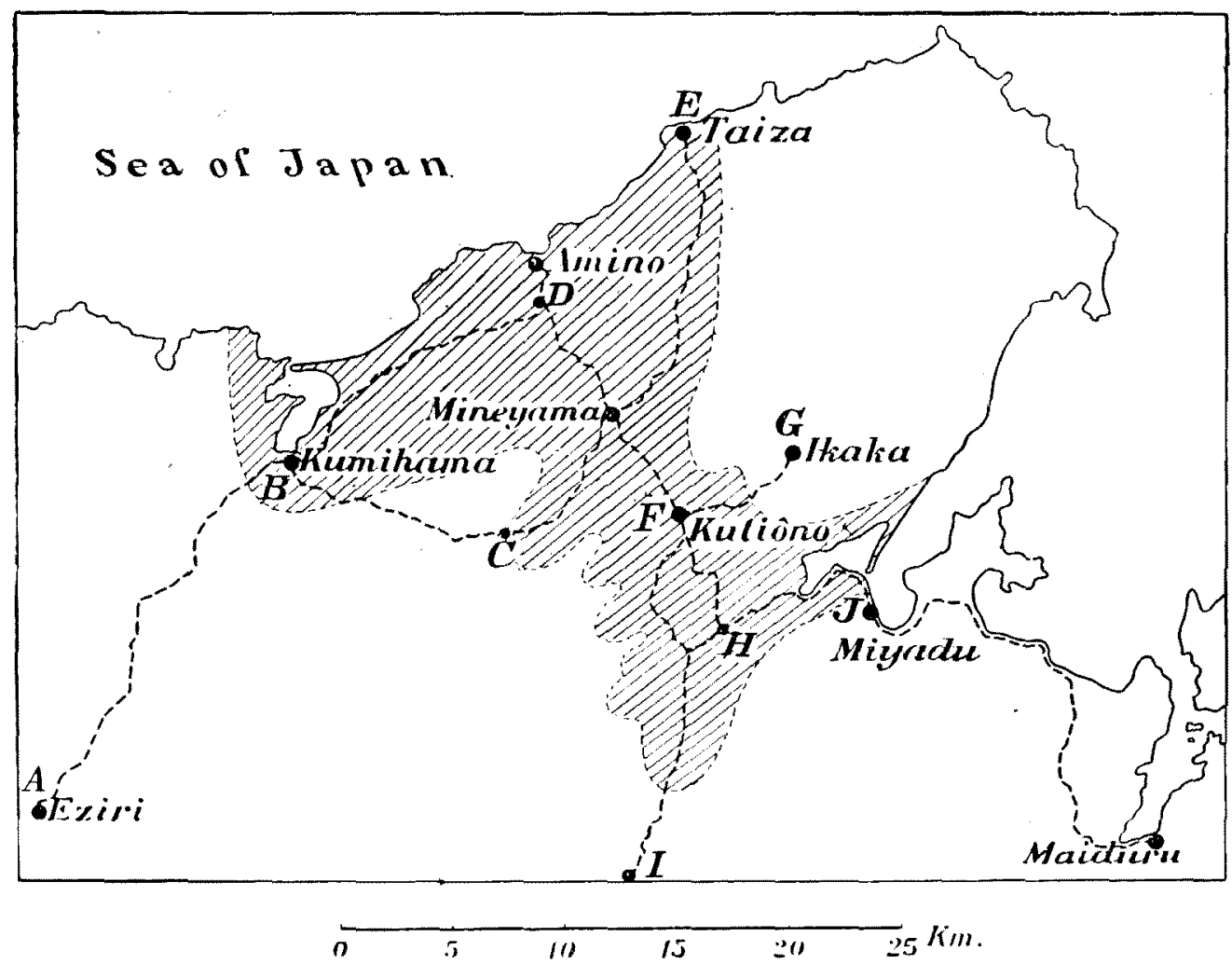

Fig. 1. _-___ Levelling Routes

IIIIIII/ Meizoseismal Area (After N. Yamasaki and F. Tada.)

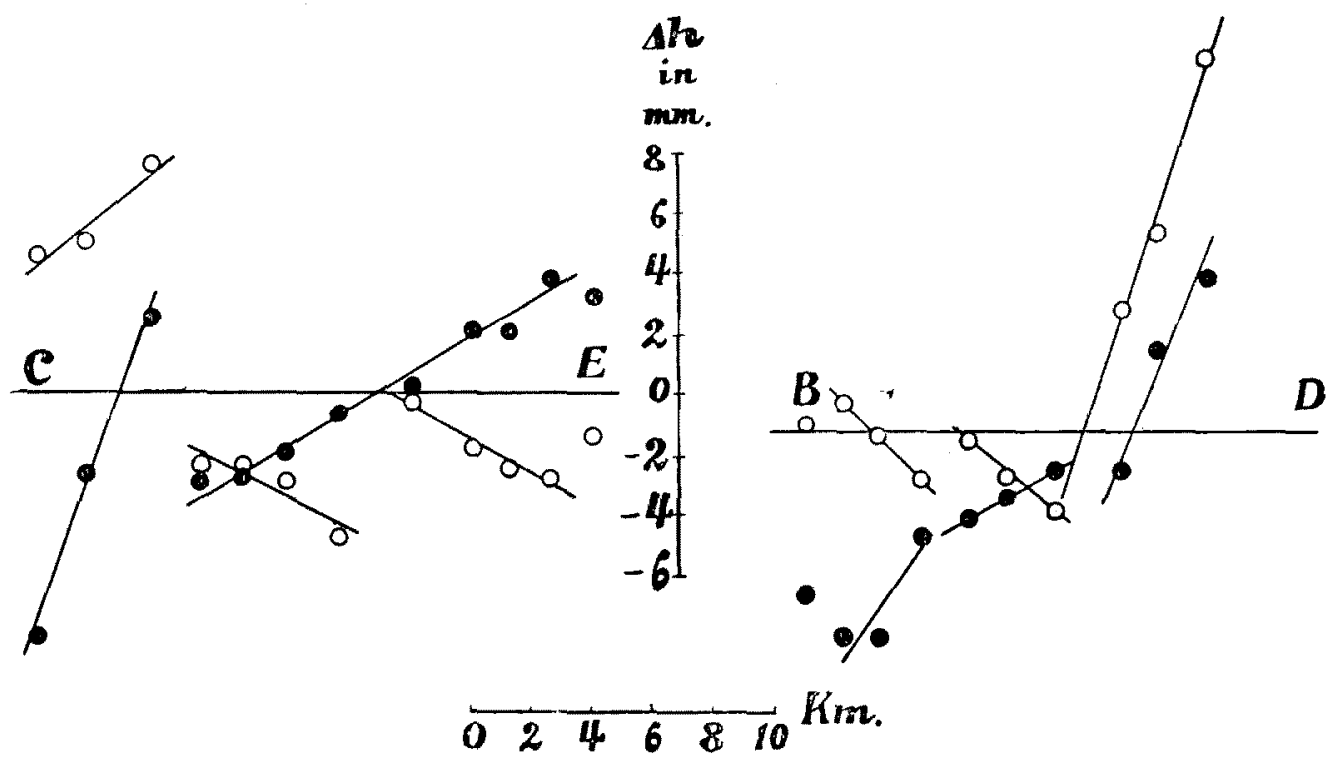

Fig. 2. $\bigcirc \Delta$ between the 1st and 2nd levellings.

- $\Delta h$ between the 2nd and 3rd levellings. 
As is seen in Fig. 2, the points representing the vertical displacements of the bench marks are arranged on a set of broken lines, and the joints of these lines are located at the same abscissa in both series of graphs corresponding to the different epochs of levellings.

The earth crust in this district must therefore be regarded to be made up of a number of structural units with the boundaries which correspond to the joints of the segments in Fig. 2. The bench marks lying on one and the same structural unit are rigidly connected to each other being only subjected to a common tilting, upheaval, depression etc. of the unit as a whole.

In Fig. 3, the structural units as revealed by the above analysis are shown by hatchings of different directions, their horizontal extensions being mostly from 5 to $10 \mathrm{kms}$.

On the other hand, the geological structure of the Tango district has been investigated by many workers in special connection with the recent earthquake. Through the efforts of these workers, a number of younger faults as well as geologically weak lines were found to run in different directions in this district. Consulting the results of these investigations, all the boundaries of the assumed structural units are found to fall exactly on the lines of the younger faults or geologically
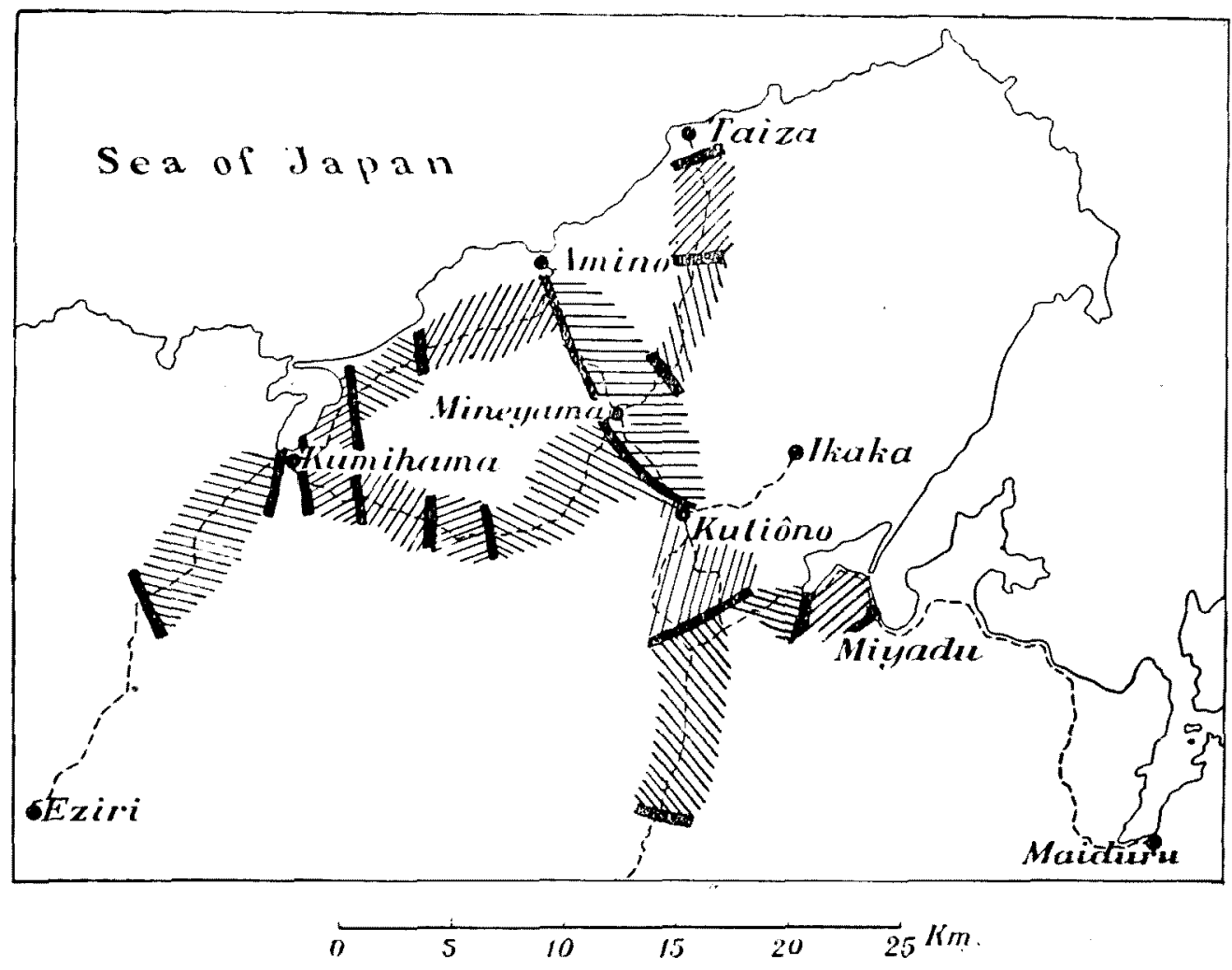

Fig. 3. I/IIIII/II Structural Unit 
weak lines. It must therefore be concluded that these preexisting faults are still in their states of activity and each structural unit of the crust bordered by these lines is subjected to its own movement. It is quite a remarkable fact that the tectonic structure of the crust still persists in its significance even in such a minor and temporary movement as is here dealt with.

Finally attention is called to the remarkable fact that the senses of tilting of some of the structural units are inverted in the different epochs of the surveys. The coupling of a structural unit with its neighbours must therefore be very loose, and each of the units must have been able to move with comparative ease at least immediately after the great earthquake.

In the course of the present study, the writer had many occasions to talk about the present problem with Professors T. Terada, M. Ishimoto, S. Tsuboi, Messrs. F. Tada and H. Tsuya, which were very useful for him. The writer wishes to express his indebtness to these gentlemen for their kind advices and instructions. 